\title{
Radioimmunotherapy: A Specific Treatment Protocol for Cancer by Cytotoxic Radioisotopes Conjugated to Antibodies
}

\author{
Hidekazu Kawashima \\ Department of Radiopharmaceutical Chemistry, Faculty of Pharmaceutical Sciences, Health Sciences University of Hokkaido, \\ 1757 Kanazawa, Tobetsu-cho, Ishikari-gun, Hokkaido 061-0293, Japan
}

Correspondence should be addressed to Hidekazu Kawashima; kawashima@hoku-iryo-u.ac.jp

Received 27 June 2014; Accepted 4 August 2014; Published 14 October 2014

Academic Editor: Masahiro Ono

Copyright (C) 2014 Hidekazu Kawashima. This is an open access article distributed under the Creative Commons Attribution License, which permits unrestricted use, distribution, and reproduction in any medium, provided the original work is properly cited.

\begin{abstract}
Radioimmunotherapy (RIT) represents a selective internal radiation therapy, that is, the use of radionuclides conjugated to tumor-directed monoclonal antibodies (including those fragments) or peptides. In a clinical field, two successful examples of this treatment protocol are currently extended by ${ }^{90} \mathrm{Y}$-ibritumomab tiuxetan (Zevalin) and ${ }^{131}$ I-tositumomab (Bexxar), both of which are anti-CD20 monoclonal antibodies coupled to cytotoxic radioisotopes and are approved for the treatment of non-Hodgkin lymphoma patients. In addition, some beneficial observations are obtained in preclinical studies targeting solid tumors. To date, in order to reduce the unnecessary exposure and to enhance the therapeutic efficacy, various biological, chemical, and treatment procedural improvements have been investigated in RIT. This review outlines the fundamentals of RIT and current knowledge of the preclinical/clinical trials for cancer treatment.
\end{abstract}

\section{What Is Radioimmunotherapy (RIT)?}

Antibodies (Abs) are glycoproteins secreted from plasma B cell and are used by immune system to identify and remove foreign pathogens such as bacteria and viruses. Because it is considered that Abs also have cytotoxic potency against some malignant tumor cells, the therapeutic efficacy in cancer has been examined. However, intact Abs are insufficient to improve patient survival rate dramatically. As a one approach to enhance the therapeutic response by using immunological technique, cytotoxic radioisotopes ( $\alpha$ - or $\beta$-particle emitters) are conjugated to Abs or the fragments. This strategy is employed to deliver radioisotopes to the targeting tissue by appropriate vehicle. After the radiolabeled Abs bind to receptors/tumor antigens expressed on the surface of cancerous tissue, cells within an anatomic region of the $\alpha$ - or $\beta$-range will be killed.

In a clinical field, systemic radiotherapy using naked radioisotope (iodine-131: ${ }^{131} \mathrm{I}$ ) was first performed by Hertz to patient of Graves' disease in 1941 [1]. Then, investigations on the use of Abs coupled with adequate radioisotopes subsequently emerged in the early 1950s [2,3]. Though direct radioiodinated Abs were mainly used in the initial clinical studies, progress in chelation chemistry has enabled the utilization of many therapeutic metal radioisotopes that possess inherent radiation properties. Various combinations of Abs and radioisotopes have been examined, which results in the adaptation in different clinical situations [4, 5]. RIT involves the application of radiolabeled monoclonal Abs (mAbs) to molecular targeted therapy [6]. Both the use of directly labeled $\mathrm{mAbs}$ and in vivo label of tumor-binding $\mathrm{mAbs}$ by conjugation-pretargeting method have been developed.

Irradiated cells absorb high amounts of energy in the form of photons or charged particles, which promote the direct macromolecular damage as well as the generation of reactive oxygen and/or nitrogen species [7]. Both free radicals and molecular oxygen damage DNA strand $[8,9]$, and the damage induces not only apoptosis [10] but also programmed necrosis [11]. Because the ranges in tissue of ionizing radiations are rather large compared with a typical cell size, uniform binding of the radioimmunoconjugates is not a prerequisite for its efficacy. In other words, adjacent cells not expressing the receptors/tumor antigens can also be killed 
TABLE 1: Radioisotopes used in RIT.

\begin{tabular}{|c|c|c|c|}
\hline Radioisotope & Energy $_{\max }(\mathrm{MeV})$ & Range & Half-life \\
\hline \multicolumn{4}{|c|}{$\beta$-Particle emitter } \\
\hline${ }^{67} \mathrm{Cu}$ & 0.58 & $2.1 \mathrm{~mm}$ & $2.6 \mathrm{~d}$ \\
\hline${ }^{90} \mathrm{Y}$ & 2.28 & $12.0 \mathrm{~mm}$ & $2.7 \mathrm{~d}$ \\
\hline${ }^{131} \mathrm{I}$ & 0.61 & $2.0 \mathrm{~mm}$ & $8.0 \mathrm{~d}$ \\
\hline${ }^{177} \mathrm{Lu}$ & 0.50 & $1.5 \mathrm{~mm}$ & $6.7 \mathrm{~d}$ \\
\hline${ }^{186} \mathrm{Re}$ & 1.07 & $4.5 \mathrm{~mm}$ & $3.7 \mathrm{~d}$ \\
\hline${ }^{188} \mathrm{Re}$ & 2.12 & $10.4 \mathrm{~mm}$ & $16.9 \mathrm{hr}$ \\
\hline \multicolumn{4}{|c|}{$\alpha$-Particle emitter } \\
\hline${ }^{211}$ At & 6.8 & $80 \mu \mathrm{m}$ & $7.2 \mathrm{hr}$ \\
\hline${ }^{213} \mathrm{Bi}$ & 8.3 & $84 \mu \mathrm{m}$ & $46 \mathrm{~min}$ \\
\hline${ }^{225} \mathrm{Ac}$ & $6.0 \sim 8.0$ & $60 \sim 90 \mu \mathrm{m}$ & $10.0 \mathrm{~d}$ \\
\hline \multicolumn{4}{|c|}{ Auger-electron emitter } \\
\hline${ }^{125} \mathrm{I}$ & & $2 \sim 500 \mathrm{~nm}$ & $60.5 \mathrm{~d}$ \\
\hline
\end{tabular}

by the physical cross-fire effect. This means continuous lowdose irradiation from radiolabeled Abs cause lethal effects on nearby normal cells. Moreover, it is reported that RITs also evoke the normalization of tumor vasculature [12], presumably owing to facilitation of immune cell migration towards the malignant lesions [13].

For therapy, therefore, $\alpha$ - or $\beta$-particle emitters are preferable. Vehicles coupled with radioisotopes emitting Auger electrons are also available; however, they need to be localized close to DNA due to the very short range of these radiations [14-16]. Simultaneous emission of $\gamma(\mathrm{X})$ rays, which are suitable for imaging, will help measure pharmacokinetic parameters and calculate dosimetry of the radioimmunoconjugates. Table 1 shows radioisotopes commonly used for RIT.

Among them, relatively well-studied and practical radioisotopes are the $\beta$-emitters ${ }^{131} \mathrm{I}$, yttrium-90 $\left({ }^{90} \mathrm{Y}\right)$, and lutetium-177 $\left({ }^{177} \mathrm{Lu}\right)$. Radioisotope to use is selected by consideration of those radiophysical properties (energy and half-life) as well as the labeling chemistry. For example, ${ }^{90} \mathrm{Y}$ possesses a higher $\beta$-particle $E_{\max }$ and a shorter half-life when compared with ${ }^{131} \mathrm{I}$. On the other hand, metal ${ }^{90} \mathrm{Y}$ should be conjugated to Ab via chelating agent, whereas ${ }^{131} \mathrm{I}$ can form a carbon-iodine bond directly. Lutetium-177 has radiophysical properties similar to ${ }^{131} \mathrm{I}$ and radiolabeling chemistry similar to ${ }^{90} \mathrm{Y}$.

Investigations of RIT using $\alpha$-particle emitters also have been developed. Because $\alpha$-particle gives its energy to the surrounding molecules within a narrow range $(<100 \mu \mathrm{m}$, equivalent to a few cell diameters), it leads to high linear energy transfer (high LET) within the target and less bystander effect to nontarget tissues compared to Abs labeled with $\beta$-emitters. In addition to the high LET, which leads to the high relative biological effectiveness (RBE) [17], recent studies have shown that cytotoxic efficacy of $\alpha$-particle is independent of the local oxygen concentration and cell cycle state [18]. Bismuth-213 $\left({ }^{213} \mathrm{Bi}\right)$, astatine-211 $\left({ }^{211} \mathrm{At}\right)$, and actinium-225 $\left({ }^{225} \mathrm{Ac}\right)$ are well investigated in $\alpha$-particle RIT [19-22].
Compared to external beam radiation therapy, one of the most potent advantages of RIT is the ability to attack not only the primary tumor but also lesions systemically metastasizing. In addition, targeted radiotherapy using specific vehicle agents is extremely valuable in cases of (1) residual micrometastatic lesions, (2) residual tumor margins after surgical resection, (3) tumors in the circulating blood including hematologic malignancy, and (4) malignancies that present as free-floating cells [23].

Brief data on current RITs provided in this review paper is summarized in Table 2.

\section{Direct Method}

The success of RIT depends on the selective accumulation of cytotoxic radioisotopes at affected areas. Fundamental properties required for vehicles against a particular biomarker are (1) high binding affinity to the intended target, (2) high specificity, (3) high tumor to background ratio, (4) high metabolic stability, and (5) low immunogenicity [24, 25]. From the viewpoint of those molecular characteristics, Abs have been considered as suitable agent for the delivery of therapeutic radioisotopes. Moreover, the development of hybridoma technology in 1975 allowed taking advantage of mAbs in RIT [26].

"Direct method" requires direct conjugation of cytotoxic radioisotopes to various antitumor $\mathrm{mAbs}$ (or their fragments) via an appropriate chelator and the single-step administration to patients. Consequently, many antigenic determinants (mostly on the cell surface) have been targeted by Abs. On the other hand, one of the most critical obstacles to achieve high background ratio in this application is the slow clearance of Abs from the blood and nontarget tissues due to their high molecular weight $[27,28]$. Abs will disappear from plasma very slowly, which encourages higher tumor uptake; however, a longer duration is needed to reach the maximum tumor to normal radioactivity ratio. Radiation dose for treating patient increases time-dependently, which results in the exposure of radioactive bone marrow leading to the hematologic toxicity. Therefore, structural diversification of Abs has been attempted to improve the pharmacokinetic properties. Lower molecular weight fragments of conventional Abs including $\mathrm{F}\left(\mathrm{ab}^{\prime}\right)_{2}$, Fab or its multivalent conjugate, minibody, diabody, and single chain variable fragments ( $\mathrm{scFv}$ ) could be utilized, which retain the essential antigen binding properties and obtain more rapid clearance rates than intact mAbs. Those smaller types of constructs can traverse the vascular channels, resulting in a more rapid tumor uptake and a faster blood clearance than parental Abs [29, 30], possessing potencies to achieve superior tumor to background ratios. In general, however, affinities of small $\mathrm{Ab}$ forms to tumor antigen are lower than those of Abs, and, moreover, too fast blood clearance of peptides yields less time to interact with the target. Therefore, absolute tumor uptake for these constructs is lower than those of Abs. Further development of the engineered forms holding both favorable pharmacokinetics 


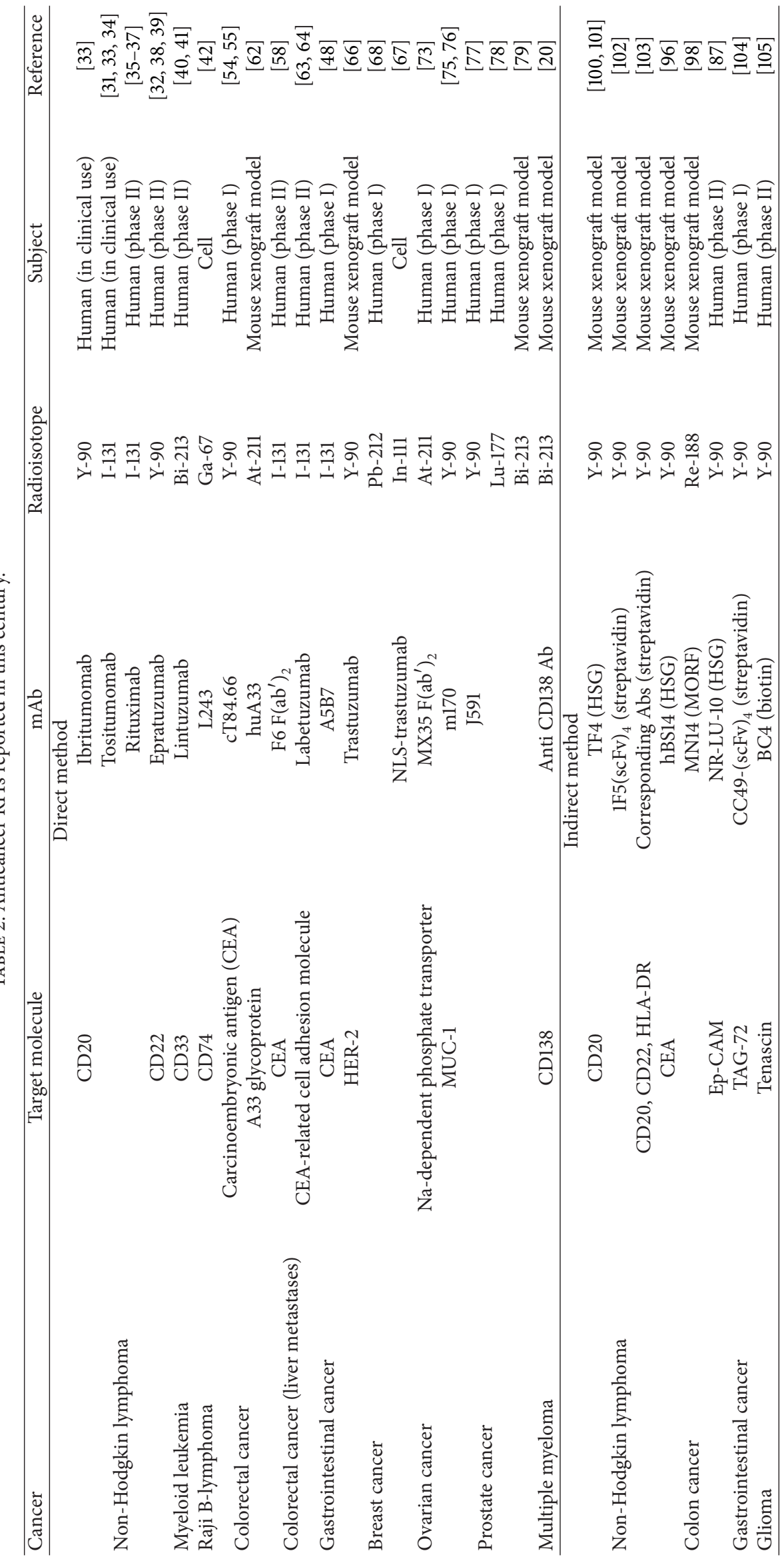


and tumor uptake is desired. Radiolabeled peptides targeting intended tumor can be available due to the preferable pharmacokinetics and low antigenicity. In this approach, control of the affinity (specific accumulation) of radiolabeled conjugates to tumor tissue is also important.

2.1. Hematological Cancers. It is reported that anticancer responses occur at relatively low radiation-absorbed doses (i.e., less than $10 \mathrm{~Gy}$ ) in non-Hodgkin lymphoma (NHL) $[31,32] .{ }^{90}$ Y-ibritumomab tiuxetan (Zevalin) and ${ }^{131} \mathrm{I}-$ tositumomab (Bexxar) are the two FDA-approved radiolabeled anti-CD20 murine Abs that have been administered to patients with NHL $[33,34]$. However, neither treatment is applied to patients with more than $25 \%$ bone marrow involvement because these patients might suffer from more severe hematologic toxicity. Several other radiolabeled Abs have been tested in hematological cancers. A ${ }^{131}$ I-labeled anti-CD20 mAb ( ${ }^{131}$ I-rituximab) [35-37] and an ${ }^{90}$ Y-labeled anti-CD22 $\mathrm{mAb}\left({ }^{90} \mathrm{Y}\right.$-epratuzumab tetraxetan) $[32,38,39]$ are in advanced clinical trials.

Shorter-range radioisotopes ( $\alpha$-particle emitters) can be a better option for the treatment of patients with hematological cancer. In previous investigations, RIT using ${ }^{213} \mathrm{Bi}$-labeled anti-CD33 IgG was performed in myeloid leukemia [40, 41]; however, short physical half-life of ${ }^{213} \mathrm{Bi}$ poses a problem for conjugate preparation. Thus, longer-lived emitters, such as ${ }^{211}$ At or ${ }^{225} \mathrm{Ac}$, which can emit four daughter $\alpha$-particles during its decay, might be available. RITs using Augeremitters, such as iodine-125 $\left({ }^{125} \mathrm{I}\right)$, gallium-67 $\left({ }^{67} \mathrm{Ga}\right)$, and indium-111 $\left({ }^{111} \mathrm{In}\right)$, could be suitable for micrometastatic disease. Potential cytotoxicity of ${ }^{67} \mathrm{Ga}$-labeled anti-CD74 Ab was observed in a study using Raji B-lymphoma cells [42].

Due to the expression of these targeting antigens, normal $B$ cells also have potencies to bind to the radiolabeled Abs. Thus, at low protein doses, the radioimmunoconjugates would be trapped to spleen rapidly, where a considerable number of $B$ cells exist. To avoid this issue, unconjugated $A b$ is sometimes added to the system, which blocks the unfavorable distribution [43-45]. In addition, these Abs can enhance a tumor cell's sensitivity to radiation and chemotherapy [4648], and thus, therapeutic responses would be achieved by a combination of the unconjugated $\mathrm{Ab}$ and targeted radiation.

2.2. Solid Cancers. RIT as a treatment protocol could be useful in the therapy for nonhematological cancers as well; however, convincing therapeutic outcomes have not been obtained yet in patients with solid cancer. One of the most obvious issues with RITs in solid cancers is that, unlike lymphoma, most of the Abs used are unable to affect tumor growth. To elicit clinical benefits for patients with advanced and/or disseminated solid cancers, several designs of the treatment are being undertaken: improvement of $\mathrm{Ab}$ uptake and enhancement of radiosensitization of cancer cells [49-51].
Here, some examples of RITs targeting solid cancer are shown.

2.2.1. Colorectal Cancer. Owing to the early characterization and ubiquitous expression in colorectal cancer, carcinoembryonic antigen (CEA) [52] has been the most common target for RIT in this disease. cT84.66, a chimeric IgG against the A3 epitope of CEA, possesses highly selective affinity to cancer cells expressing CEA [53]. RIT using ${ }^{90} \mathrm{Y}$-cT84.66 was performed by Wong et al. [54, 55], with minor responses in tumor regression. Several other murine anti-CEA RIT agents have been evaluated, including ${ }^{131} \mathrm{I}-\mathrm{NP}-4 \mathrm{~F}\left(\mathrm{ab}^{\prime}\right)_{2},{ }^{131} \mathrm{I}-\mathrm{F} 6$ $\mathrm{F}\left(\mathrm{ab}^{\prime}\right)_{2},{ }^{131} \mathrm{I}-\mathrm{A} 5 \mathrm{~B} 7,{ }^{131} \mathrm{I}-\mathrm{COL}-1$, and ${ }^{186}$ Re-NR-CO-02 F $\left(\mathrm{ab}^{\prime}\right)_{2}$ $[50,56-60]$.

A33, one of the glycoproteins, is expressed homogeneously in more than 95\% of all colorectal cancers [61] and thus the humanized $\mathrm{Ab}$ (huA33) has been developed. Preclinical studies using ${ }^{211}$ At-labeled huA33 indicate that the uptake in tumor was found to be specific to the presence of A33 antigen [62].

In a trial study performed by Liersch et al., patients having undergone liver resection for metastatic colorectal cancer were treated with ${ }^{131}$ I-labeled humanized anti-CEACAM5 $\operatorname{IgG}[63]$. Median survival of patients having received RIT was significantly longer than that of control subjects [64].

2.2.2. Breast Cancer/Ovarian Cancer. Trastuzumab is a humanized IgG $\mathrm{mAb}$ directed against the extracellular domain of the human epidermal growth factor receptor 2 (HER-2)/neu that is commonly overexpressed in breast, ovarian, and gastrointestinal tumors [65]. This $\mathrm{Ab}$ has been labeled with several radioisotopes such as ${ }^{90} \mathrm{Y}[66]$ and ${ }^{111} \mathrm{In}$ [67], for clinical study of breast cancer. Phase I study of intraperitoneal ${ }^{212} \mathrm{~Pb}$-trastuzumab for patients with advanced ovarian cancer is also ongoing [68].

MUC-1, a mucin epitope, is commonly expressed on the surface of breast cancer cells. Schrier et al. reported on a phase I study using the murine Ab labeled with ${ }^{90} \mathrm{Y}\left({ }^{90} \mathrm{Y}\right.$ MX-DTPA-BrE-3) and autologous stem cell rescue in patients with breast cancer [69]. One-half of the patients exhibited objective partial response to the therapy. To overcome the limitation of repeated dosing, an ${ }^{90} \mathrm{Y}$-labeled humanized $\mathrm{Ab}$ has also been evaluated for use with stem cell support [70].

Cell-surface sodium-dependent phosphate transport protein $2 \mathrm{~b}$, which is highly expressed on ovarian cancer cells, is recognized by the murine IgG MX35 [71, 72]. The potential usefulness of this $\mathrm{Ab}$ has been established in preclinical models, and then intraperitoneal administration of ${ }^{211} \mathrm{At}-\mathrm{MX} 35 \quad \mathrm{~F}\left(\mathrm{ab}^{\prime}\right)_{2}$ was undertaken to a phase I trial to determine the pharmacokinetics, dosimetry, and toxicity [73].

2.2.3. Prostate Cancer. MUC-1, described above for its use in breast cancer, has also been shown to be upregulated in androgen-independent prostate cancer cells, making it a good target for RIT [74]. m170, a murine $\mathrm{mAb}$, was labeled with ${ }^{90} \mathrm{Y}$, which was examined in patients with metastatic, 
androgen-independent prostate cancer [75]. Many patients who complain of pain at the entry of study reported a significant reduction in pain following therapy. A phase I study of ${ }^{90}$ Y-2IT-BAD-ml70 combined with low-dose paclitaxel was also performed by the same group [76].

$\mathrm{J} 591$ is an IgG $\mathrm{mAb}$ against the extracellular domain of prostate-specific membrane antigen (PSMA). Several J591 constructs labeled with ${ }^{90} \mathrm{Y}$ [77], ${ }^{177} \mathrm{Lu}$ [78], and ${ }^{213} \mathrm{Bi}$ [79] have also been evaluated in patients with prostate cancer.

\section{Indirect Method}

In "indirect method," directly radiolabeled mAbs are not used; that is, mAbs and radioactive effector molecules are administered separately and they will be conjugated in vivo. This technique can improve target to nontarget ratio to achieve high imaging contrast and/or therapeutic efficacy. In a field of RIT, this strategy is referred to as pretargeted radioimmunotherapy (PRIT) and was developed to avoid the issues associated with the prolonged residence times of radiolabeled $\mathrm{Ab}$ in 1980s [80, 81].

PRIT is a technique that enables the Ab localization phase to be temporally separated from the radioisotope administration in the form of a small molecular hapten. This approach involves the sequential administration of (1) a bispecific $\mathrm{mAb}$ derivative (bs-mAb) capable of binding a tumor antigen and a chelate and (2) a small molecular weight radiolabeled effector species. The radiolabeled species is administered following a scheduled lag period to allow the bs-mAbs to accumulate to the target site and any residual bs-mAbs are cleared from the circulation. The bs-mAb is not radiolabeled directly, and thus no exposure would occur during "unlabeled" bsmAbs localize to the tumor by themselves. In some cases, an additional "clearing molecule," which removes unbound bs-mAb from the circulation, is administered prior to the radiolabeled effector. Consequently, improvement of tumor to background ratios has been achieved $[82,83]$. Summarized scheme is shown in Figure 1.

A key to successful implementation of the pretargeting method consists of the high target specificity and affinity offered by bs-mAb and the superior pharmacokinetic characteristics of a low molecular weight compound. The small size and inert properties of the radiolabeled effector allow it to distribute easily in the fluidic volume and then to be eliminated rapidly, thereby decreasing the overall radiation burden to nontarget organs and tissues such as bone marrow [84]. Also, PRIT increases the dose rate to the cancer as compared with a RIT by using directly radiolabeled IgG that takes 1-2 days to reach maximum distribution.

To ensure the two parts (bs-mAb and radiolabeled effector) bind to each other strongly upon interaction at cancerous region, each must be suitably modified with complementary reactive species. One of the approaches is based on avidin or streptavidin in conjunction with biotin in a variety of configurations [85]. Avidins could bind as many as four biotin molecules with very high binding constant $\left(10^{-15} \mathrm{M}\right)$, and, thus, some avidin/biotin-based PRIT were examined clinically [86-88]. In this protocol, clearing agent was injected to remove residual streptavidinated Abs from the blood. The primary issue with PRIT depending on avidin (streptavidin) is the immunogenicity of these foreign proteins $[89,90]$.

Conjugation of radioisotopes to bs-mAb is controlled by another constituent. The approach has been utilized with a bs-mAb to histamine-succinyl-glycine (HSG) [91, 92]. By joining two haptens via a short peptide, uptake and retention of the radiolabeled effector (divalent hapten-peptide) would be enhanced locally within the cancer compared with those of the monovalent form [93-95]. Di-HSG-peptide structures have been developed for binding several radioisotopes, including ${ }^{90} \mathrm{Y}$ and ${ }^{99 \mathrm{~m}} \mathrm{Tc}[96,97]$. Other methods employ complementary synthetic low immunogenic DNA analogs, morpholinos, as bridging agents $[98,99]$.

3.1. PRIT for Hematological Cancers. In preclinical studies, pretargeting method showed better responses with much less hematologic toxicity and thus represents a significant improvement over the RIA using anti-CD20 IgG agents radiolabeled directly [100].

Among the hematological cancers, NHL therapy has been examined in detail by pretargeting. In conventional NHL model mice, PRIT with a tri-Fab fragment followed by ${ }^{90} \mathrm{Y}$-labeled effector led to dramatic cure rates compared to RIT with direct ${ }^{90} \mathrm{Y}$-veltuzumab, which is a radiolabeled anti-CD20 Ab [101]. Similar therapeutic responses were also achieved using the streptavidin-biotin format of PRIT in the Ramos lymphoma model, using a combination of anti-CD20 Ab-streptavidin fusion protein $1 \mathrm{~F} 5(\mathrm{scFv})_{4} \mathrm{SA}$ and ${ }^{90}$ Y-DOTA-biotin [102]. Pagel et al. compared therapeutic efficacy between direct RIT and PRIT in xenograft models of lymphoma using CD20, CD22, and MHC class II cell surface receptor (HLA-DR) as the targets. In this study, PRIT by the streptavidin-biotin conjugation showed higher therapeutic indices and superior tumor regression [103].

3.2. PRIT for Solid Cancers. A phase II trial was examined with ${ }^{90}$ Y-DOTA-biotin pretargeted with a NR-LU-10, an anti-Ep-CAM (epithelial glycoprotein-2) IgG-streptavidin conjugate in advanced colorectal cancer [87]; however, no significant responses were observed. More recently, a recombinant protein of streptavidin with four CC49 (anti-tumorassociated glycoprotein 72: anti-TAG-72) single chains and ${ }^{90}$ Y-labeled biotin pair has been tested in patients with gastrointestinal malignancy [104].

In a field of brain tumor, patients with grade III glioma and glioblastoma were pretargeted with ${ }^{90} \mathrm{Y}$-labeled biotin, resulting in a significant extension of survival in the PRIT subjects [105].

\section{Concluding Remarks}

Because Ab-based targeted radiation is considered to mediate direct cytotoxic effects, RIT (PRIT) could provide us with opportunities for safer and more efficient cancer treatment. Indeed, these techniques have been extensively used as conventional anticancer strategies. Especially, RIT (PRIT) has been effective in hematological cancers. There are also 


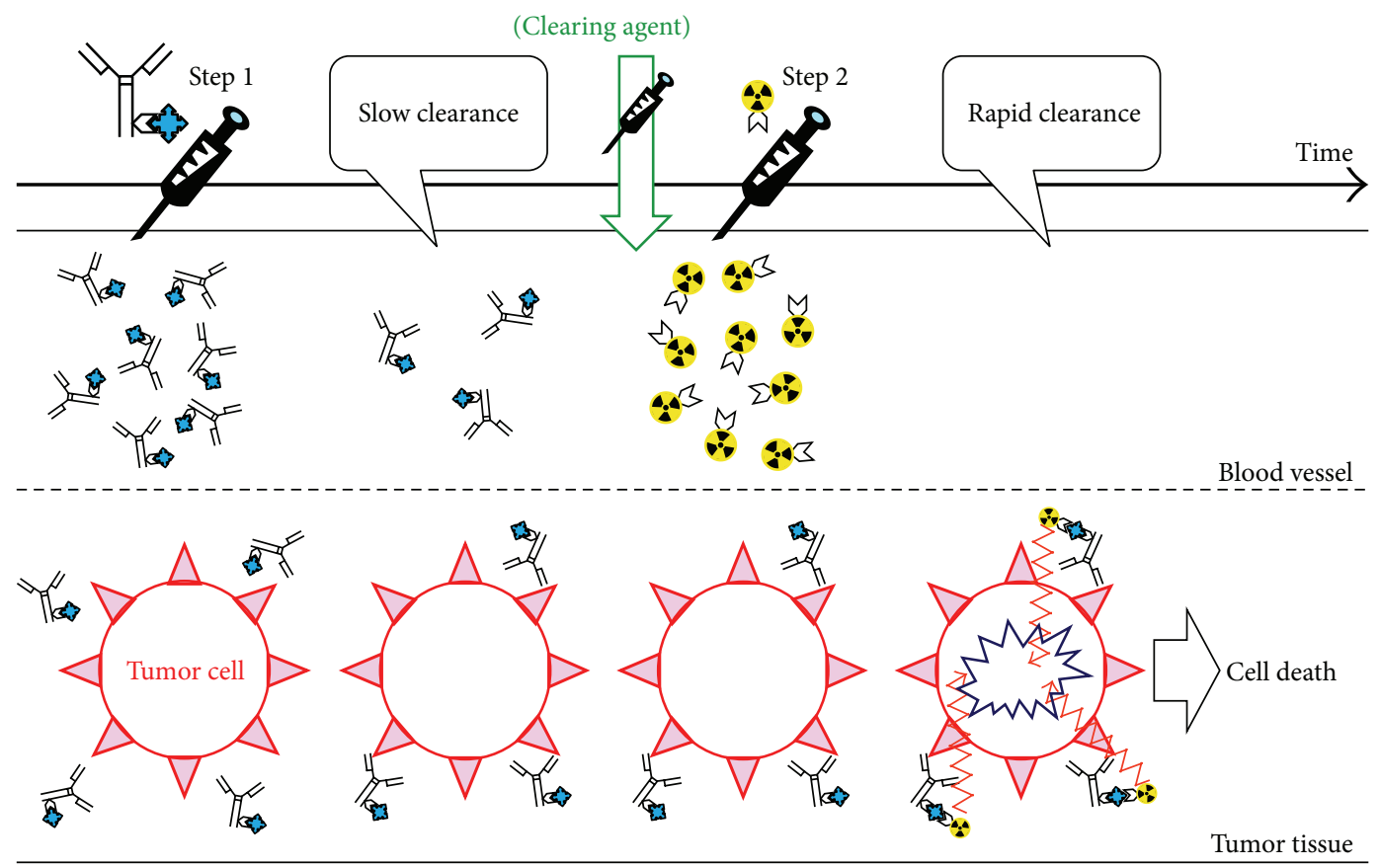

FIGURE 1: Schematic diagram of pretargeting approach.

developments of new immunostimulant for lymphoma that is combined with RIT (PRIT), which can enhance the overall therapeutic response.

On the contrary, responses to RIT (PRIT) are generally low in solid cancer and it might be due to the unconventional microenvironments. Oxygen concentrations less than $0.02 \%$ decrease the vulnerability of cancer cells to ionizing radiation [106], and even milder hypoxia produces a substantial level of resistance to irradiation [107]. Strategies to radiosensitize the lesions by means of an increased supply of oxygen or treatment of nitroimidazole analog [108] would help enhance the efficacy of RIT (PRIT).

RIT (PRIT) is a valuable treatment modality which can detect and quantify the accumulation of therapeutic agents readily. Thus, molecular imaging approach can be adapted to select patients, to decide the treatment strategy, and to assess the therapeutic benefit. Developments of novel Abbased targeted therapeutics and the combination with other interventions should support cancer therapy in future.

\section{Conflict of Interests}

The author declares that there is no conflict of interests regarding the publication of this paper.

\section{References}

[1] P. Fragu, "How the field of thyroid endocrinology developed in france after World War II," Bulletin of the History of Medicine, vol. 77, no. 2, pp. 393-414, 2003.

[2] D. Pressman and L. Korngold, "The in vivo localization of antiWagner-osteogenic-sarcoma antibodies," Cancer, vol. 6, no. 3, pp. 619-623, 1953.
[3] R. W. Wissler, P. A. Barker, M. H. Flax et al., "A study of the preparation, localization, and effects of antitumor antibodies labeled with $\mathrm{I}^{131}$," Cancer Research, vol. 16, no. 8, pp. 761-773, 1956.

[4] O. A. Gansow, M. W. Brechbiel, S. Mirzadeh, D. Colcher, and M. Roselli, "Chelates and antibodies: current methods and new directions," Cancer Treatment and Research, vol. 51, pp. 153-171, 1990.

[5] M. K. Moi, S. J. DeNardo, and C. F. Meares, "Stable bifunctional chelates of metals used in radiotherapy," Cancer Research, vol. 50, no. 3, pp. S789-S793, 1990.

[6] D. M. Goldenberg and R. M. Sharkey, "Advances in cancer therapy with radiolabeled monoclonal antibodies," The Quarterly Journal of Nuclear Medicine and Molecular Imaging, vol. 50, no. 4, pp. 248-264, 2006.

[7] K. M. Prise and J. M. O'Sullivan, "Radiation-induced bystander signalling in cancer therapy," Nature Reviews Cancer, vol. 9, no. 5, pp. 351-360, 2009.

[8] J. A. Bertout, S. A. Patel, and M. C. Simon, "The impact of $\mathrm{O}_{2}$ availability on human cancer," Nature Reviews Cancer, vol. 8, no. 12, pp. 967-975, 2008.

[9] P. Vaupel and A. Mayer, "Hypoxia in cancer: significance and impact on clinical outcome," Cancer and Metastasis Reviews, vol. 26, no. 2, pp. 225-239, 2007.

[10] G. Kroemer, L. Galluzzi, and C. Brenner, "Mitochondrial membrane permeabilization in cell death," Physiological Reviews, vol. 87, no. 1, pp. 99-163, 2007.

[11] L. Cabon, P. Galán-Malo, A. Bouharrour et al., "BID regulates AIF-mediated caspase-independent necroptosis by promoting BAX activation," Cell Death and Differentiation, vol. 19, no. 2, pp. 245-256, 2012.

[12] R. Ganss, E. Ryschich, E. Klar, B. Arnold, and G. J. Hämmerling, "Combination of T-cell therapy and trigger of inflammation induces remodeling of the vasculature and tumor eradication," Cancer Research, vol. 62, no. 5, pp. 1462-1470, 2002. 
[13] E. Tartour, H. Pere, B. Maillere et al., "Angiogenesis and immunity: a bidirectional link potentially relevant for the monitoring of antiangiogenic therapy and the development of novel therapeutic combination with immunotherapy," Cancer and Metastasis Reviews, vol. 30, no. 1, pp. 83-95, 2011.

[14] R. W. Howell, "Auger processes in the 21st century," International Journal of Radiation Biology, vol. 84, no. 12, pp. 959-975, 2008.

[15] M. J. Mattes, "Radionuclide-antibody conjugates for single-cell cytotoxicity," Cancer, vol. 94, no. 4, pp. 1215-1223, 2002.

[16] G. L. Ong, S. E. Elsamra, D. M. Goldenberg, and M. Jules Mattes, "Single-cell cytotoxicity with radiolabeled antibodies," Clinical Cancer Research, vol. 7, no. 1, pp. 192-201, 2001.

[17] A. K. Claesson, B. Stenerlöw, L. Jacobsson, and K. Elmroth, "Relative biological effectiveness of the $\alpha$-particle emitter ${ }^{211}$ At for double-strand break induction in human fibroblasts," Radiation Research, vol. 167, no. 3, pp. 312-318, 2007.

[18] E. J. Hall and A. J. Giaccia, Radiology for the Radiologist, Lippincott Williams \& Wilkins, Philadelphia, Pa, USA, 7th edition, 2007.

[19] M. R. McDevitt, G. Sgouros, R. D. Finn et al., "Radioimmunotherapy with $\alpha$-emitting nuclides," European Journal of Nuclear Medicine, vol. 25, no. 9, pp. 1341-1351, 1998.

[20] M. Chérel, S. Gouard, J. Gaschet et al., " ${ }^{213}$ Bi radioimmunotherapy with an anti-mCD138 monoclonal antibody in a murine model of multiple myeloma," The Journal of Nuclear Medicine, vol. 54, no. 9, pp. 1597-1604, 2013.

[21] G. Vaidyanathan and M. R. Zalutsky, "Astatine radiopharmaceuticals: prospects and problems," Current Radiopharmaceuticals, vol. 1, no. 3, pp. 177-196, 2008.

[22] M. Miederer, D. A. Scheinberg, and M. R. McDevitt, "Realizing the potential of the Actinium-225 radionuclide generator in targeted alpha particle therapy applications," Advanced Drug Delivery Reviews, vol. 60, no. 12, pp. 1371-1382, 2008.

[23] M. L. Sautter-Bihl, G. Herbold, and H. Bihl, "Minimal residual disease: a target for radioimmunotherapy with ${ }^{131} \mathrm{I}-$ labeled monoclonal antibodies? Some dosimetric considerations," Recent Results in Cancer Research, vol. 141, pp. 67-75, 1996.

[24] K. Chen and X. Chen, "Design and development of molecular imaging probes," Current Topics in Medicinal Chemistry, vol. 10, no. 12, pp. 1227-1236, 2010.

[25] K. Chen and P. S. Conti, "Target-specific delivery of peptidebased probes for PET imaging," Advanced Drug Delivery Reviews, vol. 62, no. 11, pp. 1005-1022, 2010.

[26] G. Köhler and C. Milstein, "Continuous cultures of fused cells secreting antibody of predefined specificity," Nature, vol. 256, no. 5517, pp. 495-497, 1975.

[27] J. L. Murray, M. G. Rosenblum, L. Lamki et al., "Clinical parameters related to optimal tumor localization of indium-111labeled mouse antimelanoma monoclonal antibody ZME-018," The Journal of Nuclear Medicine, vol. 28, no. 1, pp. 25-33, 1987.

[28] S. F. Rosebrough, Z. D. Grossman, J. G. McAfee et al., "Thrombus imaging with Indium-111 and Iodine-131-labeled fibrin-specific monoclonal antibody and its $\mathrm{F}(\mathrm{ab})_{2}$ and Fab fragments," The Journal of Nuclear Medicine, vol. 29, no. 7, pp. 1212-1222, 1988.

[29] A. M. Wu and P. D. Senter, "Arming antibodies: prospects and challenges for immunoconjugates," Nature Biotechnology, vol. 23, no. 9, pp. 1137-1146, 2005.

[30] L. A. Maleki, B. Baradaran, and J. Majidi, "Future prospects of monoclonal antibodies as magic bullets in immunotherapy," Human Antibodies, vol. 22, no. 1-2, pp. 9-13, 2013.
[31] G. Sgouros, S. Squeri, A. M. Ballangrud et al., "Patient-specific, 3-dimensional dosimetry in non-Hodgkin's lymphoma patients treated with ${ }^{131}$ I-anti-B1 antibody: assessment of tumor doseresponse," The Journal of Nuclear Medicine, vol. 44, no. 2, pp. 260-268, 2003.

[32] R. M. Sharkey, A. Brenner, J. Burton et al., "Radioimmunotherapy of non-Hodgkin's lymphoma with ${ }^{90}$ Y-DOTA humanized anti-CD22 IgG ( ${ }^{90}$ Y-Epratuzumab): do tumor targeting and dosimetry predict therapeutic response?" The Journal of Nuclear Medicine, vol. 44, no. 12, pp. 2000-2018, 2003.

[33] S. J. Goldsmith, "Radioimmunotherapy of lymphoma: bexxar and zevalin," Seminars in Nuclear Medicine, vol. 40, no. 2, pp. 122-135, 2010.

[34] M. S. Kaminski, M. Tuck, J. Estes et al., " ${ }^{131}$ I-tositumomab therapy as initial treatment for follicular lymphoma," The New England Journal of Medicine, vol. 352, no. 5, pp. 441-449, 2005.

[35] M. F. Leahy and J. H. Turner, "Radioimmunotherapy of relapsed indolent non-Hodgkin lymphoma with ${ }^{131}$ I-rituximab in routine clinical practice: 10-year single-institution experience of 142 consecutive patients," Blood, vol. 117, no. 1, pp. 45-52, 2011.

[36] J. H. Turner, A. A. Martindale, J. Boucek, P. G. Claringbold, and M. F. Leahy, " ${ }^{131}$ I-anti CD20 radioimmunotherapy of relapsed or refractory non-Hodgkins lymphoma: a phase II clinical trial of a nonmyeloablative dose regimen of chimeric rituximab radiolabeled in a hospital," Cancer Biotherapy of Radiopharmaceuticals, vol. 18, no. 4, pp. 513-524, 2003.

[37] T. M. Illidge, M. Bayne, N. S. Brown et al., "Phase $1 / 2$ study of fractionated ${ }^{131}$ I-rituximab in low-grade B-cell lymphoma: the effect of prior rituximab dosing and tumor burden on subsequent radioimmunotherapy," Blood, vol. 113, no. 7, pp. 1412-1421, 2009.

[38] F. Morschhauser, F. Kraeber-Bodéré, W. A. Wegener et al., "High rates of durable responses with anti-CD22 fractionated radioimmunotherapy: results of a multicenter, phase I/II study in non-Hodgkin's lymphoma," Journal of Clinical Oncology, vol. 28, no. 23, pp. 3709-3716, 2010.

[39] G. L. Griffiths, S. V. Govindan, R. M. Sharkey, D. R. Fisher, and D. M. Goldenberg, " ${ }^{90}$ Y-DOTA-hLL2: an agent for radioimmunotherapy of non-Hodgkin's lymphoma," The Journal of Nuclear Medicine, vol. 44, no. 1, pp. 77-84, 2003.

[40] G. Sgouros, Å. M. Ballangrud, J. G. Jurcic et al., "Pharmacokinetics and dosimetry of an $\alpha$-particle emitter labeled antibody: ${ }^{213} \mathrm{Bi}-\mathrm{HuM} 195$ (anti-CD33) in patients with leukemia," The Journal of Nuclear Medicine, vol. 40, no. 11, pp. 1935-1946, 1999.

[41] J. G. Jurcic, S. M. Larson, G. Sgouros et al., "Targeted $\alpha$ particle immunotherapy for myeloid leukemia," Blood, vol. 100, no. 4, pp. 1233-1239, 2002.

[42] R. B. Michel, M. W. Brechbiel, and M. J. Mattes, "A comparison of 4 radionuclides conjugated to antibodies for single-cell kill," The Journal of Nuclear Medicine, vol. 44, no. 4, pp. 632-640, 2003.

[43] M. S. Kaminski, K. R. Zasadny, I. R. Francis et al., "Iodine-131anti-B1 radioimmunotherapy for B-cell lymphoma," Journal of Clinical Oncology, vol. 14, no. 7, pp. 1974-1981, 1996.

[44] P. McLaughlin, A. J. Grillo-López, B. K. Link et al., "Rituximab chimeric anti-CD20 monoclonal antibody therapy for relapsed indolent lymphoma: half of patients respond to a four-dose treatment program," Journal of Clinical Oncology, vol. 16, no. 8, pp. 2825-2833, 1998.

[45] T. E. Witzig, C. A. White, G. A. Wiseman et al., "Phase I/II trial of IDEC-Y2B8 radioimmunotherapy for treatment of relapsed 
or refractory CD20 $0^{+}$B-cell non-Hodgkin's lymphoma," Journal of Clinical Oncology, vol. 17, no. 12, pp. 3793-3803, 1999.

[46] Y. Du, J. Honeychurch, M. S. Cragg et al., "Antibody-induced intracellular signaling works in combination with radiation to eradicate lymphoma in radioimmunotherapy," Blood, vol. 103, no. 4, pp. 1485-1494, 2004.

[47] N. S. Kapadia, J. M. Engles, and R. L. Wahl, "In vitro evaluation of radioprotective and radiosensitizing effects of rituximab," The Journal of Nuclear Medicine, vol. 49, no. 4, pp. 674-678, 2008.

[48] A. Ivanov, S. Krysov, M. S. Cragg, and T. Illidge, "Radiation therapy with tositumomab (B1) anti-CD20 monoclonal antibody initiates extracellular signal-regulated kinase/mitogenactivated protein kinase-dependent cell death that overcomes resistance to apoptosis," Clinical Cancer Research, vol. 14, no. 15, pp. 4925-4934, 2008.

[49] R. F. Meredith, M. B. Khazaeli, W. E. Plott et al., "Phase II study of dual ${ }^{131}$ I-labeled monoclonal antibody therapy with interferon in patients with metastatic colorectal cancer," Clinical Cancer Research, vol. 2, no. 11, pp. 1811-1818, 1996.

[50] T. Meyer, A. M. Gaya, G. Dancey et al., "A phase I trial of radioimmunotherapy with ${ }^{131} \mathrm{I}$-A5B7 anti-CEA antibody in combination with combretastatin-A4-phosphate in advanced gastrointestinal carcinomas," Clinical Cancer Research, vol. 15, no. 13, pp. 4484-4492, 2009.

[51] F. Kraeber-Bodéré, C. Bodet-Milin, C. Niaudet et al., "Comparative toxicity and efficacy of combined radioimmunotherapy and antiangiogenic therapy in carcinoembryonic antigenexpressing medullary thyroid cancer xenograft," The Journal of Nuclear Medicine, vol. 51, no. 4, pp. 624-631, 2010.

[52] P. Gold and S. O. Freedman, "Demonstration of tumor-specific antigens in human colonic carcinomata by immunological tolerance and absorption techniques," The Journal of Experimental Medicine, vol. 121, pp. 439-462, 1965.

[53] J. D. Beatty, R. B. Duda, L. E. Williams et al., "Preoperative imaging of colorectal carcinoma with ${ }^{111}$ In-labeled anticarcinoembryonic antigen monoclonal antibody," Cancer Research, vol. 46, no. 12, pp. 6494-6502, 1986.

[54] J. Y. C. Wong, S. Shibata, L. E. Williams et al., "A phase I trial of ${ }^{90} \mathrm{Y}$-anticarcinoembryonic antigen chimeric T84.66 radioimmunotherapy with 5 -fluorouracil in patients with metastatic colorectal cancer," Clinical Cancer Research, vol. 9, no. 16, pp. 5842-5852, 2003.

[55] J. Y. C. Wong, D. Z. Chu, L. E. Williams et al., "A phase I trial of ${ }^{90}$ Y-DOTA-anti-CEA chimeric T84.66 (cT84.66) radioimmunotherapy in patients with metastatic CEA-producing malignancies," Cancer Biotherapy and Radiopharmaceuticals, vol. 21, no. 2, pp. 88-100, 2006.

[56] T. M. Behr, R. M. Sharkey, M. E. Juweid et al., "Phase I/II clinical radioimmunotherapy with an iodine-131-labeled anticarcinoembryonic antigen murine monoclonal antibody IgG," The Journal of Nuclear Medicine, vol. 38, no. 6, pp. 858-870, 1997.

[57] M. E. Juweid, R. M. Sharkey, T. Behr et al., "Radioimmunotherapy of patients with small-volume tumors using iodine-131labeled anti-CEA monoclonal antibody NP-4 F $\left(\mathrm{ab}^{\prime}\right)_{2}$," The Journal of Nuclear Medicine, vol. 37, no. 9, pp. 1504-1510, 1996.

[58] M. Ychou, D. Azria, C. Menkarios et al., "Adjuvant radioimmunotherapy trial with iodine-131-labeled anticarcinoembryonic antigen monoclonal antibody $\mathrm{F} 6 \mathrm{~F}\left(\mathrm{ab}^{\prime}\right)_{2}$ after resection of liver metastases from colorectal cancer," Clinical Cancer Research, vol. 14, no. 11, pp. 3487-3493, 2008.
[59] B. Yu, J. Carrasquillo, D. Milenic et al., "Phase I trial of iodine 131-labeled COL-1 in patients with gastrointestinal malignancies: influence of serum carcinoembryonic antigen and tumor bulk on pharmacokinetics," Journal of Clinical Oncology, vol. 14, no. 6, pp. 1798-1809, 1996.

[60] H. B. Breitz, P. L. Weiden, J.-L. Vanderheyden et al., "Clinical experience with rhenium-186-labeled monoclonal antibodies for radioimmunotherapy: results of Phase I trials," The Journal of Nuclear Medicine, vol. 33, no. 6, pp. 1099-1112, 1992.

[61] P. Garin-Chesa, J. Sakamoto, S. Welt, F. X. Real, W. J. Rettig, and L. J. Old, "Organ-specific expression of the colon cancer antigen A33, a cell surface target for antibody-based therapy," International Journal of Oncology, vol. 9, no. 3, pp. 465-471, 1996.

[62] Y. Almqvist, A. C. Steffen, H. Lundqvist, H. Jensen, V. Tolmachev, and A. Sundin, "Biodistribution of ${ }^{211}$ At-labeled humanized monoclonal antibody A33," Cancer Biotherapy and Radiopharmaceuticals, vol. 22, no. 4, pp. 480-487, 2007.

[63] T. Liersch, J. Meller, B. Kulle et al., "Phase II trial of carcinoembryonic antigen radioimmunotherapy with ${ }^{131}$ I-labetuzumab after salvage resection of colorectal metastases in the liver: fiveyear safety and efficacy results," Journal of Clinical Oncology, vol. 23, no. 27, pp. 6763-6770, 2005.

[64] T. Liersch, J. Meller, M. Bittrich, B. Kulle, H. Becker, and D. M. Goldenberg, "Update of carcinoembryonic antigen radioimmunotherapy with ${ }^{131}$ I-labetuzumab after salvage resection of colorectal liver metastases: comparison of outcome to a contemporaneous control group," Annals of Surgical Oncology, vol. 14, no. 9, pp. 2577-2590, 2007.

[65] P. Carter, L. Presta, C. M. Gorman et al., "Humanization of an anti-p185HER2 antibody for human cancer therapy," Proceedings of the National Academy of Sciences of the United States of America, vol. 89, no. 10, pp. 4285-4289, 1992.

[66] D. M. Crow, L. Williams, D. Colcher, J. Y. C. Wong, A. Raubitschek, and J. E. Shively, "Combined radioimmunotherapy and chemotherapy of breast tumors with Y-90-labeled anti-Her2 and anti-CEA antibodies with taxol," Bioconjugate Chemistry, vol. 16, no. 5, pp. 1117-1125, 2005.

[67] D. L. Costantini, K. Bateman, K. McLarty, K. A. Vallis, and R. M. Reilly, “Trastuzumab-resistant breast cancer cells remain sensitive to the Auger electron-emitting radiotherapeutic agent ${ }^{111}$ In-NLS-trastuzumab and are radiosensitized by methotrexate," The Journal of Nuclear Medicine, vol. 49, no. 9, pp. 14981505, 2008.

[68] R. F. Meredith, "Safety study of ${ }^{212} \mathrm{~Pb}-\mathrm{TCMC}$-trastuzumab radio immunotherapy," http://clinicaltrials.gov/ct2/show/NCT01384253.

[69] D. M. Schrier, S. M. Stemmer, T. Johnson et al., "High-dose ${ }^{90} \mathrm{Y} \mathrm{Mx}$-diethylenetriaminepentaacetic acid (DTPA)-BrE-3 and autologous hematopoietic stem cell support (AHSCS) for the treatment of advanced breast cancer: a phase I trial," Cancer Research, vol. 55, no. 23, pp. 5921s-5924s, 1995.

[70] P. J. Cagnoni, R. L. Ceriani, W. C. Cole et al., "Phase I study of high-dose radioimmunotherapy with 90-Y-hu-BrE-3 followed by autologous stem cell support (ASCS) in patients with metastatic breast cancer," Cancer Biotherapy \& Radiopharmaceuticals, vol. 13, no. 4, p. 328, 1998.

[71] M. Welshinger, B. W. T. Yin, and K. O. Lloyd, "Initial immunochemical characterization of MX35 ovarian cancer antigen," Gynecologic Oncology, vol. 67, no. 2, pp. 188-192, 1997. 
[72] B. W. T. Yin, R. Kiyamova, R. Chua et al., "Monoclonal antibody MX35 detects the membrane transporter NaPi2b (SLC34A2) in human carcinomas," Cancer Immunity, vol. 8, article 3, 2008.

[73] H. Andersson, E. Cederkrantz, T. Bäck et al., "Intraperitoneal $\alpha$-particle radioimmunotherapy of ovarian cancer patients: pharmacokinetics and dosimetry of ${ }^{211}$ At-MX35 $\mathrm{F}\left(\mathrm{ab}^{\prime}\right)_{2}$ : A Phase I Study," The Journal of Nuclear Medicine, vol. 50, no. 7, pp. 1153-1160, 2009.

[74] S. J. DeNardo, C. M. Richman, H. Albrecht et al., "Enhancement of the therapeutic index: from nonmyeloablative and myeloablative toward pretargeted radioimmunotherapy for metastatic prostate cancer," Clinical Cancer Research, vol. 11, no. 19, pp. 7187s-7194s, 2005.

[75] R. T. O’Donnell, S. J. DeNardo, A. Yuan et al., "Radioimmunotherapy with ${ }^{111} \mathrm{In} /{ }^{90} \mathrm{Y}$-2IT-BAD-m170 for metastatic prostate cancer," Clinical Cancer Research, vol. 7, no. 6, pp. 15611568, 2001.

[76] C. M. Richman, S. J. DeNardo, R. T. O’Donnell et al., "High-dose radioimmunotherapy combined with fixed, low-dose paclitaxel in metastatic prostate and breast cancer by using a MUC-1 monoclonal antibody, m170, linked to indium-111/yttrium-90 via a cathepsin cleavable linker with cyclosporine to prevent human anti-mouse antibody," Clinical Cancer Research, vol. 11, no. 16, pp. 5920-5927, 2005.

[77] M. I. Milowsky, D. M. Nanus, L. Kostakoglu, S. Vallabhajosula, S. J. Goldsmith, and N. H. Bander, "Phase I trial of yttrium-90labeled anti-prostate-specific membrane antigen monoclonal antibody J591 for androgen-independent prostate cancer," Journal of Clinical Oncology, vol. 22, no. 13, pp. 2522-2531, 2004.

[78] N. H. Bander, M. I. Milowsky, D. M. Nanus, L. Kostakoglu, S. Vallabhajosula, and S. J. Goldsmith, "Phase I trial of ${ }^{177}$ Lutetium-labeled J591, a monoclonal antibody to prostatespecific membrane antigen, in patients with androgenindependent prostate cancer," Journal of Clinical Oncology, vol. 23, no. 21, pp. 4591-4601, 2005.

[79] M. R. McDevitt, E. Barendswaard, D. Ma et al., "An $\alpha$-particle emitting antibody ([ $\left.\left.{ }^{213} \mathrm{Bi}\right] J 591\right)$ for radioimmunotherapy of prostate cancer," Cancer Research, vol. 60, no. 21, pp. 6095-6100, 2000.

[80] D. T. Reardan, C. F. Meares, D. A. Goodwin et al., "Antibodies against metal chelates," Nature, vol. 316, no. 6025, pp. 265-268, 1985.

[81] D. A. Goodwin, C. F. Mears, M. McTigue, and G. S. David, "Monoclonal antibody hapten radiopharmaceutical delivery," Nuclear Medicine Communications, vol. 7, no. 8, pp. 569-580, 1986.

[82] D. A. Goodwin, C. F. Meares, M. J. McCall, M. McTigue, and W. Chaovapong, "Pre-targeted immunoscintigraphy of murine tumors with indium-111-labeled bifunctional haptens," The Journal of Nuclear Medicine, vol. 29, no. 2, pp. 226-234, 1988.

[83] D. M. Goldenberg, R. M. Sharkey, G. Paganelli, J. Barbet, and J. Chatal, "Antibody pretargeting advances cancer radioimmunodetection and radioimmunotherapy," Journal of Clinical Oncology, vol. 24, no. 5, pp. 823-834, 2006.

[84] B. M. Zeglis, K. K. Sevak, T. Reiner et al., "A pretargeted PET imaging strategy based on bioorthogonal diels-alder click chemistry," The Journal of Nuclear Medicine, vol. 54, no. 8, pp. 1389-1396, 2013.

[85] D. J. Hnatowich, F. Virzi, and M. Rusckowski, "Investigations of avidin and biotin for imaging applications," The Journal of Nuclear Medicine, vol. 28, no. 8, pp. 1294-1302, 1987.
[86] H. B. Breitz, P. L. Weiden, P. L. Beaumier et al., "Clinical optimization of pretargeted radioimmunotherapy with antibodystreptavidin conjugate and ${ }^{90}$ Y-DOTA-biotin," The Journal of Nuclear Medicine, vol. 41, no. 1, pp. 131-140, 2000.

[87] S. J. Knox, M. L. Goris, M. Tempero et al., "Phase II trial of yttrium-90-DOTA-biotin pretargeted by NR-LU-10 antibody/streptavidin in patients with metastatic colon cancer," Clinical Cancer Research, vol. 6, no. 2, pp. 406-414, 2000.

[88] J. Schultz, Y. Lin, J. Sanderson et al., "A tetravalent single-chain antibody-streptavidin fusion protein for pretargeted lymphoma therapy," Cancer Research, vol. 60, no. 23, pp. 6663-6669, 2000.

[89] G. Paganelli and M. Chinol, "Radioimmunotherapy: is avidinbiotin pretargeting the preferred choice among pretargeting methods?" European Journal of Nuclear Medicine and Molecular Imaging, vol. 30, no. 5, pp. 773-776, 2003.

[90] D. M. Goldenberg, C. H. Chang, R. M. Sharkey et al., "Radioimmunotherapy: is avidin-biotin pretargeting the preferred choice among pretargeting methods?" European Journal of Nuclear Medicine and Molecular Imaging, vol. 30, no. 5, pp. 777-780, 2003.

[91] E. Janevik-Ivanovska, E. Gautherot, M. Hillairet de Boisferon et al., "Bivalent hapten-bearing peptides designed for iodine-131 pretargeted radioimmunotherapy," Bioconjugate Chemistry, vol. 8, no. 4, pp. 526-533, 1997.

[92] E. A. Rossi, D. M. Goldenberg, T. M. Cardillo, W. J. McBride, R. M. Sharkey, and C. Chang, "Stably tethered multifunctional structures of defined composition made by the dock and lock method for use in cancer targeting," Proceedings of the National Academy of Sciences of the United States of America, vol. 103, no. 18, pp. 6841-6846, 2006.

[93] J.-M. le Doussal, M. Martin, E. Gautherot, M. Delaage, and J. Barbet, "In vitro and in vivo targeting of radiolabeled monovalent and divalent haptens with dual specificity monoclonal antibody conjugates: enhanced divalent hapten affinity for cellbound antibody conjugate," The Journal of Nuclear Medicine, vol. 30, no. 8, pp. 1358-1366, 1989.

[94] D. A. Goodwin, C. F. Meares, M. McTigue et al., "Pretargeted immunoscintigraphy: effect of hapten valency on murine tumor uptake," The Journal of Nuclear Medicine, vol. 33, no. 11, pp. 2006-2013, 1992.

[95] O. C. Boerman, M. H. G. C. Kranenborg, E. Oosterwijk et al., "Pretargeting of renal cell carcinoma: improved tumor targeting with a bivalent chelate," Cancer Research, vol. 59, no. 17, pp. 4400-4405, 1999.

[96] H. Karacay, P. Brard, R. M. Sharkey et al., “Therapeutic advantage of pretargeted radioimmunotherapy using a recombinant bispecific antibody in a human colon cancer xenograft," Clinical Cancer Research, vol. 11, no. 21, pp. 7879-7885, 2005.

[97] R. M. Sharkey, T. M. Cardillo, E. A. Rossi et al., "Signal amplification in molecular imaging by pretargeting a multivalent, bispecific antibody," Nature Medicine, vol. 11, no. 11, pp. 12501255, 2005.

[98] G. Liu, S. Dou, G. Mardirossian et al., "Successful radiotherapy of tumor in pretargeted mice by ${ }^{188}$ Re-radiolabeled phosphorodiamidate morpholino oligomer, a synthetic DNA analogue," Clinical Cancer Research, vol. 12, no. 16, pp. 4958-4964, 2006.

[99] G. Liu, S. Dou, P. H. Pretorius, X. Liu, M. Rusckowski, and D. J. Hnatowich, "Pretargeting CWR22 prostate tumor in mice with MORF-B72.3 antibody and radiolabeled cMORF," European Journal of Nuclear Medicine and Molecular Imaging, vol. 35, no. 2, pp. 272-280, 2008. 
[100] R. M. Sharkey, H. Karacay, C. R. Johnson et al., "Pretargeted versus directly targeted radioimmunotherapy combined with anti-CD20 antibody consolidation therapy of non-Hodgkin lymphoma," The Journal of Nuclear Medicine, vol. 50, no. 3, pp. 444-453, 2009.

[101] R. M. Sharkey, H. Karacay, S. Litwin et al., "Improved therapeutic results by pretargeted radioimmunotherapy of nonHodgkin's lymphoma with a new recombinant, trivalent, antiCD20, bispecific antibody," Cancer Research, vol. 68, no. 13, pp. 5282-5290, 2008.

[102] D. J. Green, J. M. Pagel, A. Pantelias et al., "Pretargeted radioimmunotherapy for B-cell lymphomas," Clinical Cancer Research, vol. 13, no. 18, pp. 5598s-5603s, 2007.

[103] J. M. Pagel, N. Orgun, D. K. Hamlin et al., "A comparative analysis of conventional and pretargeted radioimmunotherapy of B-cell lymphomas by targeting CD20, CD22, and HLA-DR singly and in combinations," Blood, vol. 113, no. 20, pp. 49034913, 2009.

[104] S. Shen, A. Forero, A. F. LoBuglio et al., "Patient-specific dosimetry of pretargeted radioimmunotherapy using CC49 fusion protein in patients with gastrointestinal malignancies," The Journal of Nuclear Medicine, vol. 46, no. 4, pp. 642-651, 2005.

[105] C. Grana, M. Chinol, C. Robertson et al., "Pretargeted adjuvant radioimmunotherapy with Yttrium-90-biotin in malignant glioma patients: a pilot study," British Journal of Cancer, vol. 86, no. 2, pp. 207-212, 2002.

[106] B. G. Wouters and L. D. Skarsgard, "Low-dose radiation sensitivity and induced radioresistance to cell killing in HT-29 cells is distinct from the 'adaptive response' and cannot be explained by a subpopulation of sensitive cells," Radiation Research, vol. 148, no. 5, pp. 435-442, 1997.

[107] O. Trédan, C. M. Galmarini, K. Patel, and I. F. Tannock, "Drug resistance and the solid tumor microenvironment," Journal of the National Cancer Institute, vol. 99, no. 19, pp. 1441-1454, 2007.

[108] J. Overgaard, H. S. Hansen, M. Overgaard et al., "A randomized double-blind phase III study of nimorazole as a hypoxic radiosensitizer of primary radiotherapy in supraglottic larynx and pharynx carcinoma. Results of the Danish Head and Neck Cancer Study (DAHANCA) Protocol 5-85," Radiotherapy and Oncology, vol. 46, no. 2, pp. 135-146, 1998. 


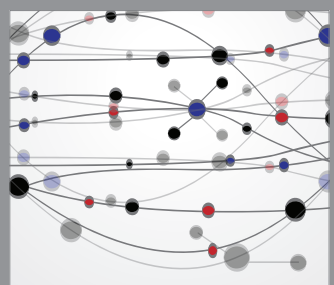

The Scientific World Journal
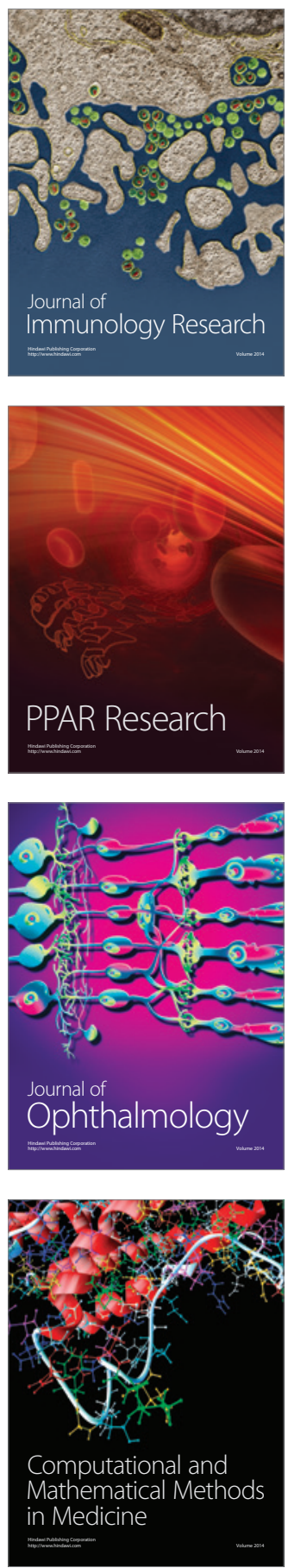

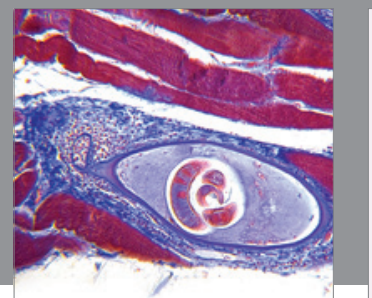

Gastroenterology

Research and Practice
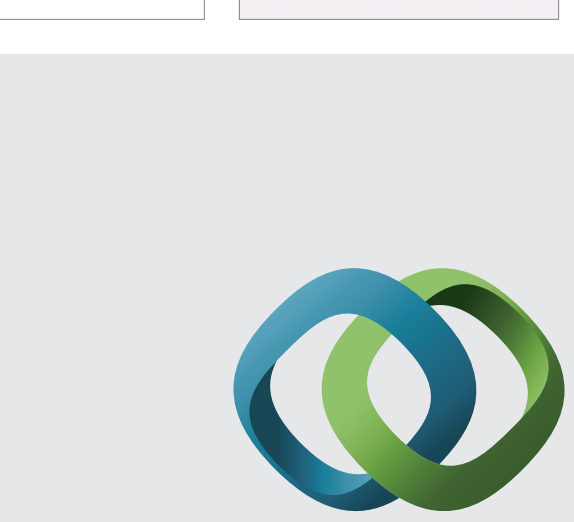

\section{Hindawi}

Submit your manuscripts at

http://www.hindawi.com
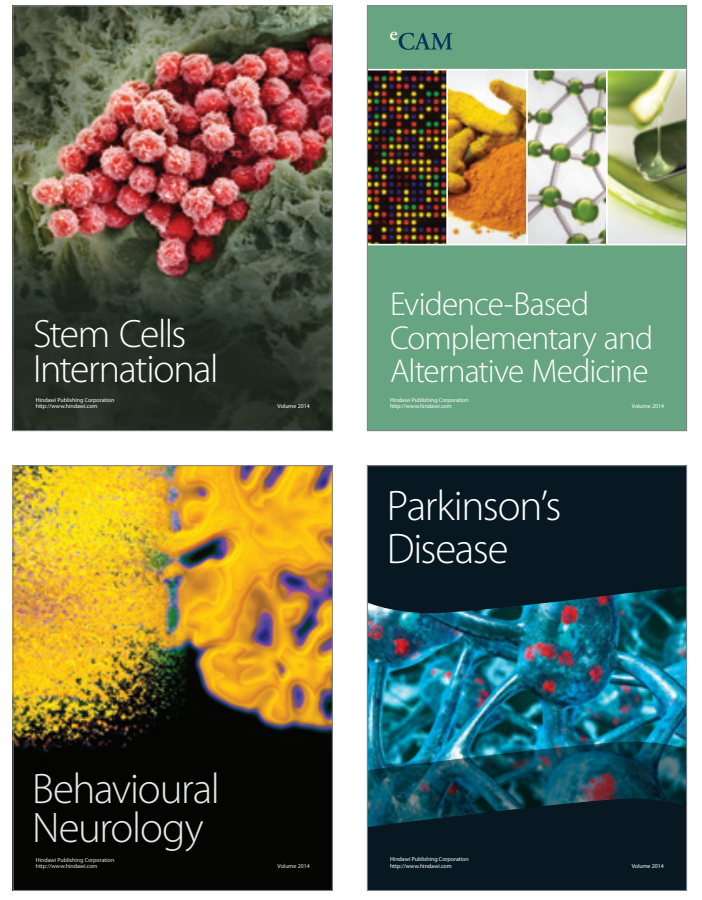
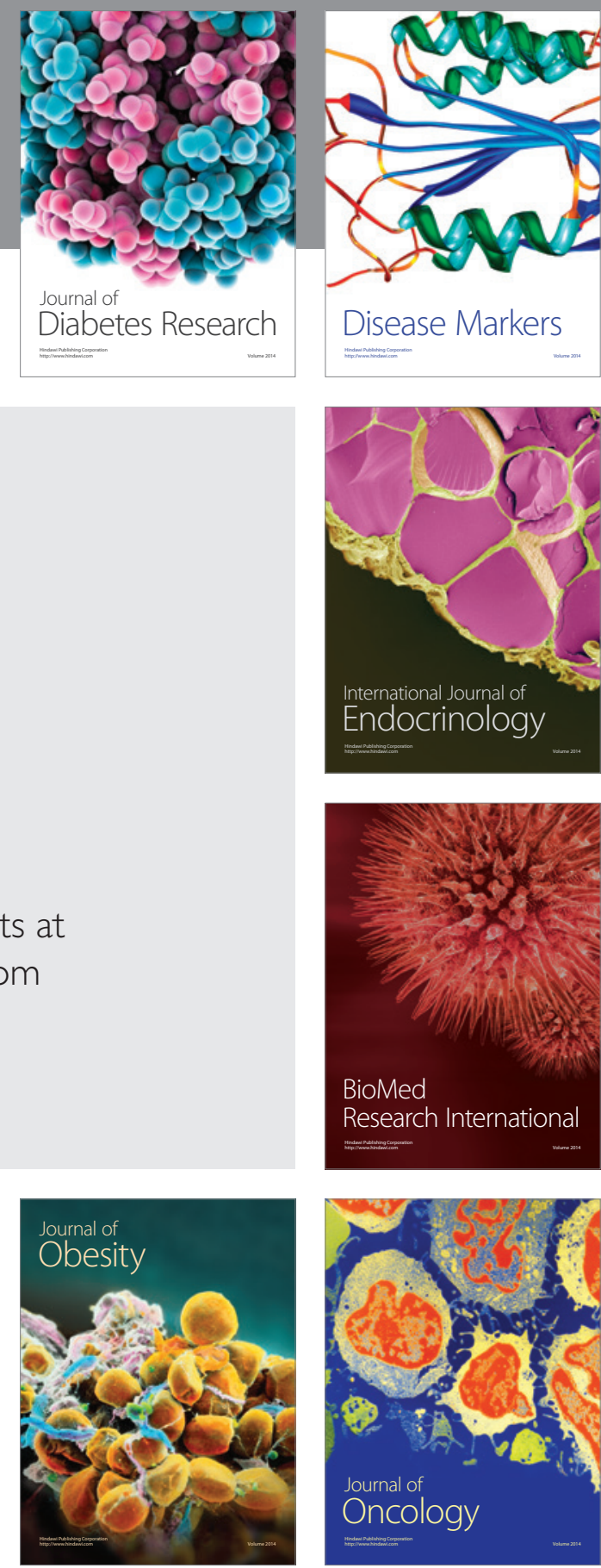

Disease Markers
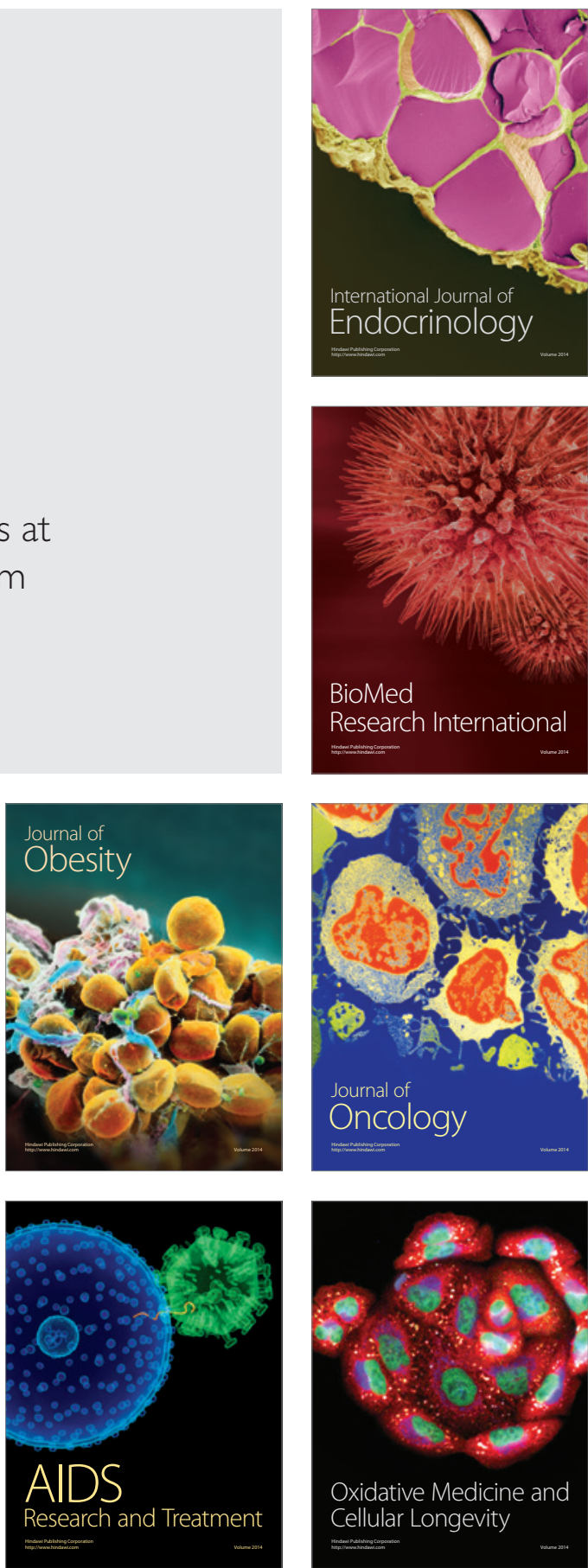